\title{
Under the surface of the agricultural entrepreneurial support ecosystems: Through the lens of complexity leadership theory
}

\author{
Jennie Cederholm Björklund, Jeaneth Johansson
}

\begin{abstract}
Agricultural advisors have recently received much critique both in practice and in the literature for not answering agricultural entrepreneurs' need for support in the ongoing industry transformation. Advisors expect to guide highly pressured agricultural entrepreneurs operating in complex settings towards sustainable businesses in highly competitive markets. The current study using complexity leadership theory goes beyond the surface of the agricultural advisors' everyday work by exploring challenges faced by the advisors and considering how to overcome them. The advisors' genuine intentions and common mission guiding the development of sustainable agricultural businesses and a vibrant countryside is not enough to achieve the goals. We identify an emergent need for innovation in the leadership of advisory work and conceptualize enabling mechanisms to accomplish such change. We suggest that the creation of adaptive space as a lubricant gives innovation the opportunity to flourish through enabling leadership.
\end{abstract}

\section{Introduction}

'For some time, there has been perceived dissatisfaction with the agricultural advice. While farmers have been critical, it has not been possible to concretize the dissatisfaction, especially beyond that the advisors know too little ${ }^{l} . '$

'Many people see the support system as something negative and ironically call it support while meaning hindrance. ${ }^{21}$

\footnotetext{
${ }^{1} \mathrm{http}: / / \mathrm{www}$. lantbruketsaffarer.se/efterlyses-radgivning-vard-namnet/

${ }^{2}$ An actor in the agricultural support ecosystem
} 
There is an urgent call among practitioners and scholars to open up the black box of the agricultural entrepreneurial support ecosystem to take agricultural entrepreneurship one step further. There is a need to acquire more knowledge on hidden aspects of the agricultural support ecosystem. Agricultural entrepreneurs globally face the pressure to transform into entrepreneurial models to improve innovativeness and survive in the highly competitive landscape (Phillipson et al. 2004). Agricultural entrepreneurs, as innovators, constantly seek new opportunities and new ways of doing things, and they need advisors' support to accomplish this. Entrepreneurs and the ecosystem surrounding them are about to change.

Although rural development programmes are continuously evaluated (e.g., Hörnsten 2017) and parts of the agricultural support ecosystem are studied from different perspectives, there is no overall picture and understanding of the roles played and the challenges faced by advisors in the ecosystem. Scholars note that knowledge about what is actually going on is scarce (Cederholm Björklund 2018; Höckert 2017). Previous studies highlight the challenges faced by advisors in the business support system (Johansson et al. 2019), but little is known about the agricultural support system. Much is known outside the entrepreneurship literature on the agricultural ecosystem at a meta-level, while the social constructions and actions taking place at a micro-level remain neglected both in general and in the entrepreneurship literature (Korsgaard et al. 2015; OECD 2018). The agricultural entrepreneurial ecosystem operates much in the shadow of what reflects 'real' entrepreneurship and is often neglected in traditional entrepreneurship literature, causing a knowledge gap (Phillipson et al. 2004). This occurs even though the sector is one of the largest worldwide, accounting for 3\% of the global GDP (FAO 2016) and employing a billion people. Only in Sweden, the agricultural sector involved 131,571 registered businesses and constituted the primary business activity of 108,886 companies $^{3}$ in 2016 (Swedish Board of Agriculture 2018a), making the Swedish case highly relevant for study. Also highlighting the relevance of the sector, the EU has allocated 351.8 billion EUR for the Common Agricultural Policy (CAP) 2014-2020, of which approximately 2.1 billion euros are allocated to Sweden (Government Offices of Sweden 2018). It is no longer possible for the agricultural entrepreneurship ecosystem, with its unique political, cultural and cognitive embeddedness, to be ignored in the entrepreneurship literature (Denzau and North 1994; Dias et al. 2018; Fitz-Koch et al. 2018; Korsgaard et al. 2015; Zukin and DiMaggio 1990). This chapter primarily focuses on the Swedish context, which is highly embedded in the European system. However, the agricultural support systems in all G20 countries are criticized for insufficient governance. They share a common need to establish long-term strategies, involve stakeholders throughout processes, clarify actors' roles, improve research and development coordination, and implement useful evaluation systems (OECD 2019).

The current study answers the call to further contextualize agricultural entrepreneurship research by highlighting the specific context of the entrepreneurial agricultural support system in general and the advisory support system in particular. We explore the roles and challenges of advisors in the support system through the lens of complexity leadership theory (CLT). We look into advisors' relational leadership and connectedness in the agriculture entrepreneurial support ecosystem (Ospina and Foldy 2010). This enables us to explore advisors' leadership in coordinating formal and informal work when operating in dynamic agricultural entrepreneurship environments where innovation is expected (cf Allen 2001; Cilliers 1998; Stacey et al. 2000).

3 Involving the Swedish standards for industrial classification, SNI 0111-0170 
The theory enables the exploration of advisors' formal and informal social interactions when dealing with new conditions. It provides a basis for exploring behaviours in the specific context of the complex adaptive system of agricultural entrepreneurship (Gartner et al. 2006; Welter 2011; Welter et al. 2017; Zahra 2007).

This study seeks to contribute to the entrepreneurship literature by exploring the environment surrounding advisors in agricultural entrepreneurship in several ways. First, we identify the roles played and challenges faced by advisors in the support ecosystem that affect advisor behaviour. We identify a strong path dependency guiding everyday practice among the actors (Nee 1998, p. 86). Many of these challenges remain tacit, and the study aims to contribute to making the ecosystem more transparent in order to enable change (Cederholm Björklund 2018). We identify formal and informal interaction patterns between key actors in the support ecosystem, e.g., governmental actors, agricultural advisory organizations, agricultural member organizations and rural societies, that impact the advice provided. We further observe the norms and values governing behaviour and fostering 'leadership practices', or collective action within and across the organizations in the system (Ospina and Foldy 2010). This exercise may contribute knowledge for the development of advisory practices and support for agricultural entrepreneurs (Phillipson et al. 2004). Second, we contribute to the conceptualization of the advisor leadership practice in agricultural entrepreneurial support systems and how everyday practice hinders the adoption of the innovation practices demanded by environmental pressure. We suggest that informal adaptive practices be adopted in order to develop the creativity and the formal administrative systems needed to develop goals and routines for challenging established practices (cf Welter 2011). Finally, we meet the need for qualitative methods in the research on agricultural entrepreneurship and advisory practice, which allows us to capture the richness and diversity of the agricultural entrepreneurial support ecosystem (Welter 2011).

\section{Contextualizing the Swedish agricultural entrepreneurship support ecosystem}

To understand the actions taking place among advisors in the agricultural entrepreneurship support ecosystem, the contextual aspects of the ecosystem, such as the nature of the actor organizations and the political and cultural embeddedness, must be outlined (Denzau and North 1994; Jack and Anderson 2002; Korsgaard et al. 2015). The present chapter acknowledges the situational boundaries embedded in the context of the Swedish agricultural entrepreneurial support ecosystem. These boundaries are connected to the historical context of the industry as a whole, strong path dependency and changes in the conditions and the nature of modern agriculture and push towards a higher degree of market and business orientation, greater competition, technology changes and digitalisation.

Swedish agriculture has changed from being highly regulated by the government, when the state coordinated price levels, to being market-driven, when Sweden joined the EU in 1995. The EU opened up a market-driven agricultural sector based on free trade both within the EU and across the world. This change occurred in many other countries as well. To address the new market conditions, management became of critical importance for agricultural entrepreneurship. Agricultural entrepreneurs need support to guide their activities in the highly competitive market and their adjustment to the continuous changes in the market (OECD 2018; Swedish Board of Agriculture 2018b). Advisors in the agricultural entrepreneurship support ecosystem expect to be prepared to guide and facilitate these changes. Accomplishing change appears to be a challenging task, as agricultural entrepreneurs find it hard to obtain the help needed from those 
whose aim is to support their entrepreneurship. The highly institutionalised Swedish agricultural support ecosystem with 200-year-old traditions is criticized for adapting poorly to support the development of sustainable agricultural business, e.g., because of limited advisory knowledge, agricultural entrepreneurship knowledge, and work methods (Höckert 2017). This chapter aims to explore the challenges faced by agricultural advisors in their work of providing guidance to agricultural entrepreneurs.

The key actors in the Swedish agricultural entrepreneurial support ecosystem consist of governmental actors, agricultural advisory organizations, agricultural member organizations and rural societies, among others. The agricultural entrepreneurship support ecosystem may at a macro level be divided into 1) a governmental system and 2) an advisory system. The governmental system outlines the boundary of the support system. Funding and regulations governing the Swedish support ecosystem mainly derive from the EU and the CAP. Reform is implemented by the CAP every 7th year to cover a period, such as 2014-2020. The governmental system channels EU funds and government-level directives via the Swedish Board of Agriculture to county administrative boards and other organizations. The value of the EU cohesion policy in the 2014-2020 programme period is EUR 351,8 billion, almost one-third of the EU budget, and approximately 2.1 billion euros of this sum have been allocated to Sweden (Government Offices of Sweden 2018). The programmes are currently under the close supervision of the EC, but the commission has signalled reform and greater opportunities for member states to control their own programmes in the future. The agricultural support ecosystem is nationally governed by the Swedish Rural Development Programme (RDP). The recently developed Swedish food strategy also guides and regulates activities in the agricultural support ecosystem at the national level.

The advisory system involves advisory organizations, such as governmental actors, associations and private organizations, which are merging into larger units. A large part of the advisory system consists of individual companies linked to a joint federation, which acts as coordinator and fosters development. The federations have no mandates for deciding for or governing the member organizations, which are all independent legal units. Actors in the agricultural support ecosystem have a common vision of contributing to agricultural entrepreneurship and sustainable rural areas, but at the same time, most of the actors are competitors. The governmental advisory organizations are as such competitors of the nongovernmental organizations. This competitive structure limits the willingness and ability of agricultural advisory support organizations to collaborate, and all organizations try to gain access to the limited resources allocated to the agricultural support system. There are governmental incentives for collaboration and knowledge sharing, but most resources are allocated towards individual activities within organizations, contradictory to the desired development (Höckert 2017; OECD 2018).

Scholars point to various challenges in agricultural support organizations, and severe problems in advisor guidance have been observed in practice and in the literature (Höckert 2017; OECD 2019). The agricultural support ecosystem is criticized for being based on subject-based knowledge and non-systematic models, and the challenges of agriculture are considered systemic (Höckert 2017). Höckert highlights the lack of space for reflection corresponding to higher loops of learning at all levels in the system. She outlines a control paradox where advisors are specialized and seldom collaborate, such that there is neither reflection nor learning within organizations. She notes the need for a broadened epistemological perspective in the advisory organizations, an extension of knowledge sharing and interplay, the creation of a collaborative culture, and, more broadly, a change from individual-based knowledge to knowledge that unites 
the knower and the knowing. The actors within the system have not managed to thoroughly describe the problems and their systemic boundaries, and the system has not reflected about what is needed to enact the change from an individual to a collaborative culture. The current study will take a further look under the surface of the agricultural entrepreneurial support ecosystem.

\section{Complexity leadership theory}

To explore beyond the surface of the complex agricultural entrepreneurship support system and the advisors' roles and challenges, we apply CLT. This framework allows us to explore the coordination and control structures of the support system. According to CLT, leadership is considered a social phenomenon involving much social interaction that causes a shift from emphasizing the human capital of the advisor and the entrepreneurs in the system to emphasizing social capital (Arena and Uhl-Bien 2016). The agricultural entrepreneurship support ecosystem is complex and involves many types of interdependent actors, such as agricultural entrepreneurs, financiers, policy makers, and scholars. The advisors expect to take the central role in the network of these key actors, who cooperate dynamically seeking common goals (Uhl-Bien et al. 2007). Leadership reaches beyond the mere leadership position and authority to encompass the management of knowledge flows within and between organizations. In line with Fleming et al. (2007), we argue that understanding the leadership in such complex adaptive systems requires a thorough understanding of the interplay within and between the key groups acting in the ecosystem.

The agricultural entrepreneurship advisory ecosystem outlines a complex adaptive system, a promising arena for key actors to meet, problem solve, learn and adopt new behaviours and ways of working (Carley and Hill 2001). Organizational adaptability, taking place in the key actors' everyday life, is a critical component for reaching goals and bringing forth new and innovative contributions to collaborative interactions (Uhl-Bien and Marion 2009). Advisors in the agricultural entrepreneurship system are considered facilitators or brokers in the system and are expected to have an active role in producing new behaviour and new ways of working (UhlBien et al. 2007). Previous studies outline the broker role as involving interactive and dynamic actions, bridging meaning by different cohesive groups and ensuring trust and information sharing (Arena and Uhl-Bien 2016).

Formal and informal control are considered as co-ordinating the interdependent structures and activities in the dynamic ecosystem. In the conceptualization of advisors' roles and challenges in the social agricultural entrepreneurship system, we depart from the three closely intertwined modes of leadership outlined in CLT, i.e., the administrative, adaptive and enabling leadership (Kontopoulos 2006; Uhl-Bien et al. 2007). The administrative modes of leadership characterize formal and bureaucratic leadership involving dynamic relationships of hierarchical top-down character. Individuals and groups plan, coordinate and expect to act effectively to reach their stated goals. The bureaucratic functions of the administrative leadership focus on aligning and controlling actions for the collective purpose, establishing structures and allocating resources to reach the stated targets and managing conflicts (Mumford et al. 2008)

Enabling leadership conceptualizes the dynamic, non-hierarchical and informal interrelations between individuals and groups of actors. The informal mode is an enabler facilitating actors in the support system to bridge the administrative and adaptive leadership functions. This mode of leadership serves as an adaptive emergent force that creates and facilitates organizational conditions to foster adaptive leadership and provides guidance in 
situations that require transition and innovation. The focus of this mode is on adaption, creativity and learning. In this way, the administrative forces and the adaptive forces may either help or oppose one another. Enabling leadership assures the transfer of knowledge and creativity from the adaptive structures to the administrative structures. The key aim is to accomplish effective adaptive leadership through enabling leadership to bridge the two types of leadership without eliminating them (Ospina and Foldy 2010).

The concept of adaptive space is a critical concept in this. Adaptive space arises between the creative adoptive system and the bureaucratic administrative system and serves as an enabler in collaborative networks, bridging the formal and informal systems (Arena and Uhl-Bien 2016; Uhl-Bien et al. 2007). The framework of CLT sets an overarching boundary for exploring and contextualizing organizational leadership in the agricultural entrepreneurial support system.

\section{Approach/method}

This study involves six types of loosely and moderated coupled national and regional key organizations in the agricultural entrepreneurship support ecosystem in Sweden. The organizations cooperate across borders to reach the common goal of nurturing agricultural entrepreneurship and the rural ecosystem. One federated organization is a joint union that includes 17 independent regional organizations. The federation coordinates and develops member organizations but cannot make decisions for or govern the members.

We used a research design triangulating data sources to understand the structures below the surface of the support ecosystem and discern the behaviour and actions of individuals and organizations. This research design enabled us to explore the tacit structures of advisor roles and challenges, making the agricultural ecosystem more transparent. We collected data through in situ observations and interviews to provide the rich contextualized data based on qualitative methods called for in the literature (Welter 2011). We observed meetings where key actors in support organizations at the regional and national levels discussed management and policy problems and challenges. In total, we observed 16 meetings involving the participation of 34 key actor organizations from the agricultural entrepreneurship support system. Fourteen of those meetings involved up to 50 participants, and two of the meetings were major meetings with between 50 and a couple hundred participants. The data were collected over a period of 8 months during 2018. Deeper knowledge of the organizations was provided through one researcher's insider access to key organizations and to native knowledge of the work processes in these organizations. This researcher collected data, attended the meetings, recorded what was said, and took notes but did not take an active role in any of the observed meetings. The observations were complemented with semi-structured interviews with key actors for follow-up and further exploration of the advisors' roles and challenges in the complex agricultural ecosystem. In total, 54 hours of effective meeting and discussion time were observed, and 3 hours of interviews were recorded. In total, 4 key actors in the support system participated in longer semi-structured interviews, and another 28 individuals from the actor organizations participated in shorter interviews.

We base the results on the data from the observations and interviews that are recorded, transcribed, inductively analysed and coded into concepts, themes and dimensions using the Gioia methodology (Gioia et al. 2012). Table 1.1 presents the coding structure and the resulting categories. We started by individually reading the transcriptions, making a broad initial coding, and briefly noting ideas. Then, through a more thorough reading, we individually identified 
statements, discussions and frames. The researchers compared their coding and proposed firstorder concepts. After discussing the findings and concepts, we identified 7 overarching themes among the first-order categories and developed second-order themes. The second-order themes identified are the lack of mutual understanding and trust, lack of collaboration, old traditions and culture, bureaucracy, individual impact/influence, co-opetition and goal congruence, and lack of strategic management and leadership. The last mentioned theme was developed during the analysis as a result of the discussions.

Table 1.1 Categorizing representative statements and first-order concepts

\section{First-order Representative statement}

Lack of

trust/uncertainty

between actors

Lack of trust/uncertainty between individuals Lack of flexibility and sensitivity

Lack of understanding of different needs and roles

Fruitless collaboration efforts Lack of overall perspective

Lack of collaborative intentions Old working methods and structure Inherited roles

Discourse reinforces the importance of traditions Focus on natural science

Innovations create
'It's complex and creates some uncertainty. The hardest thing, it's this checking, lion of... as it's called when you create fear. So, the Commission is afraid of the auditors, and Sweden is afraid of the Commission, and the Swedish government and all the way down to the County Administrative Board... and finally it ends up on the farmer.'

'It's the officers, the staff who are careful while the management had the idea that they would not be really careful, but it did not really work out.'

'We are not responsive... so maybe we could have been a bit more responsive, but I think the members want us to be fairly uncompromising.'

'The County Administrative Board is living its own little life. They think they... it will be very exciting to see... we will ask them how they handle the new management act. They have not even followed the current...'

'It's very hard between our professional categories, and it has affected our investment applications in a negative way, and our customers.'

'We're working together all the time, but then we should see... there would not be such problems with gravel in the machines. Then it would be much better. They probably collaborate de facto, but not... that's the result that counts.'

'You have to go all the way... from the time you leave until things come out at the other end. It has not worked all the way here. It's an important lesson for the whole system.'

'When there is an emergency situation, you can also add resources. But when the sun shines there is no need to collaborate.'

'Since ancient times it has been said that we should do this way.'

'We still have that tradition left...'

'What is revolutionary is that we will not have the governor as president next year... after 203 years, it feels strange.'

'It's a production specialist who manages marketing, not an educated communicator - that is the problem.'

'We have a new business development in progress... focusing on plant cultivation.'

'New solutions or innovations create almost exclusively more bureaucracy.' 
more bureaucracy

Complicated

procedures

Duplicate

application

procedures

Individual (advisor) ' 'We've learned the hard way that experience groups work better than advice.'

limitations

Interpretation of individuals in the system

'It was not so easy to do what we had planned - it did not work out according to EU regulations'.

'It's unnecessarily complicated. We know we've got this money to deal with, but we still have to apply for it.'

'This with assessments... one tries to make them transparent, but it's not easy.'

'Authorities interpret political decisions.'

Effects of

individuals in the

system (lobbies)

Individual culture,

who am I here for?

'So, we'll see what's happening, who they'll find as successor to him, and if it's still a good team of co-operation.'

'You think of yourself in the first place and do not help a colleague or help someone. Nor do you share customers or work, and you don't look for the customer's best - what the customer would need for advice, but you look at your individual budget and yourself in the first place.'

Individual mind-set 'The Swedish Board of Agriculture, they bring in new employees who ask a lot of new questions.'

'It is building relations that gives effect.'

Rural Development

Programme and

National Food

Strategy rules

The actors have

different target

groups and

assignments

'Our foundation is the Rural Development Programme.'

'The strategic goals control... but we are affected by the National Food Strategy.'

'I think we should not forget why we are applying for money... what goals we have.... instead of running at all balls'.

'It's not only agriculture in this region, it's everything that has to do with living and existing at the countryside.'

'Our members are mainly farmers.'

Most of the actors

'This old question. It's a good time to have a small talk about it. If they do are competitors this..., then we must actually have planned structured return fire.'

'That's a sensitive question. We have old relationships.'

'Still, they put too much energy inwards, so they will get even more outward and are a competitor to us in many contexts, but at the same time they are very open to cooperation. They are really very, very professional.'

After reviewing the patterns emerging from the second-order themes, we found phenomena and common issues that made it possible to connect and assemble the themes into overarching aggregated dimensions (see Figure 1.1). Three overarching dimensions were identified: a) collaborative model, b) institutionalized organizations/systems and c) strategic management. The overarching themes were coded to outline a communication platform. The next step was the development of the conceptual model (see Figure 1.2). We identified the value 
of exploring our findings with the use of CLT to gain knowledge on the social constructions and actions taking place within the support ecosystem. The communication platform was further conceptualized and attached to the themes of 1) facilitating activities, 2) enabling leadership and 3) adaptive space. The conceptual model outlines the mechanisms fostering and hindering the support ecosystem's adoption of the new practices and innovation required by the external society.

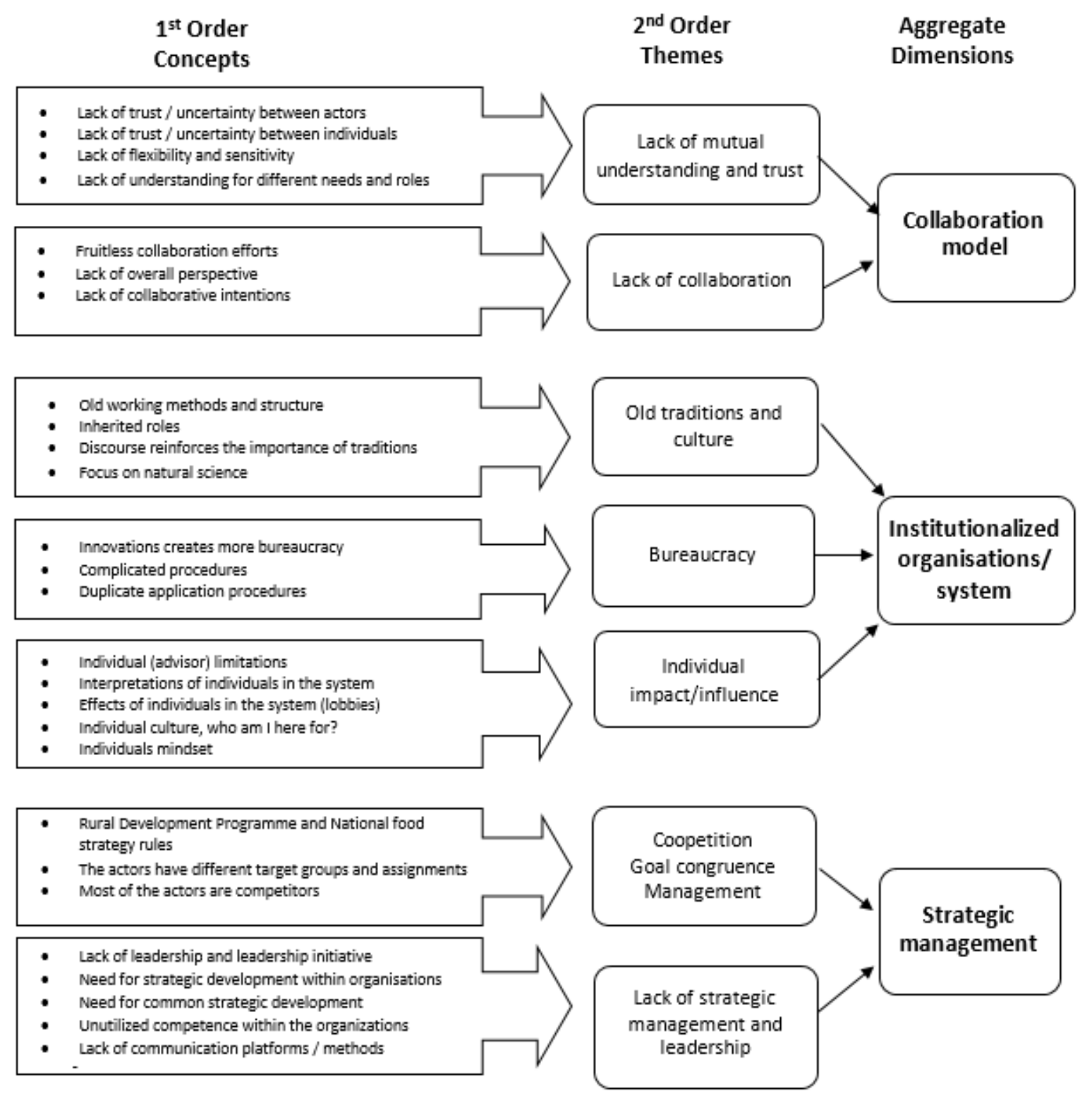

Figure 1.1 Conceptualizing challenges in the agricultural entrepreneurship support system 


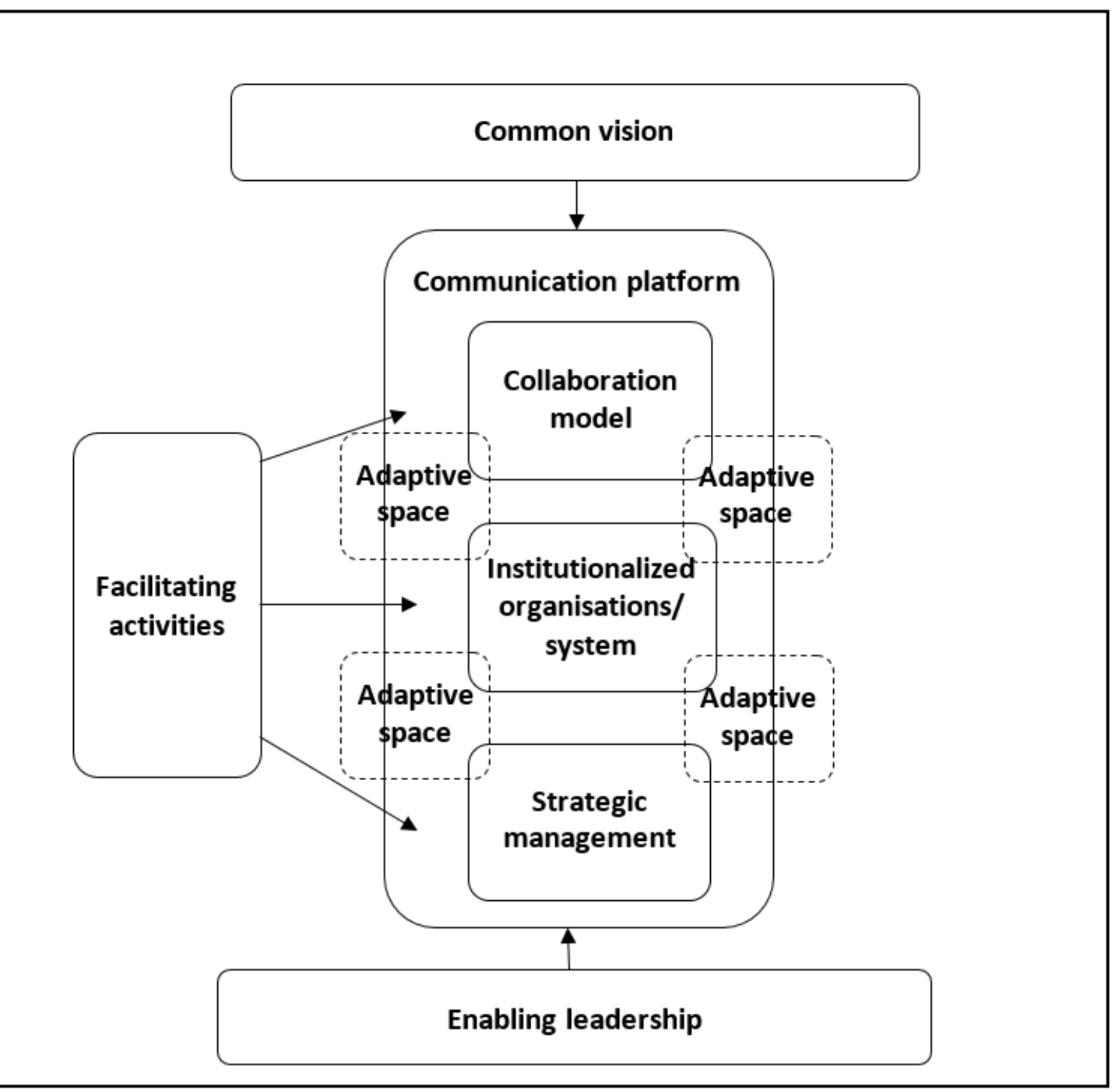

Figure 1.2 Model for enabling innovation in a sustainable rural entrepreneurial support ecosystem

We base our study on social constructivism (Berger and Luckmann 1966), where actors in the ecosystem socially construct their knowledge structures through interaction with each other. The implications are constructed in time and may as such be manifested or change over time. Knowledge arises because actors perceive the world in a certain way and act accordingly (Berger and Luckmann 1966).

\section{Empirical findings and analysis}

The agricultural entrepreneurial support ecosystem in Sweden has a common vision of contributing to a sustainable, prosperous rural society and a sustainable use of the land. 
However, the support organizations target different groups: the authorities work for the countryside, and some organizations work for their members, others for customers and still others for a mix of members and customers. The members of organizations may be, for instance, agricultural entrepreneurs. Support organizations are managed and operated in different ways, with different intentions and missions. The organizations are often managed to fulfil requirements of the food strategy, RDP and other funding organizations rather than to fulfil agriculture entrepreneurs' expressed needs. The goals and funding are typically governed by the Ministry for Rural Affairs and interpreted by officials at the Swedish Board of Agriculture at different levels. The support organizations receive income through their provision of advisory services. The main part of the organizations' funding derives from the Swedish Board of Agriculture and County and Regional Administrative Boards. The organizations that aim to collaborate in the support system also compete for the same source of funding.

The funding that governs the Swedish support ecosystem derives largely from the EU. However, new directives propose greater national self-determination, and representatives from different organizations have gathered to discuss possibilities and common challenges. They try to interpret the future by discussing potential scenarios.

'A re-nationalization, moving the system to the Member States, is challenging. What will happen? There are opportunities.'

'The idea is to set targets at the EU level. It is up to the Member States to find solutions. The question is how Sweden manages to handle it, given how detailed everything was before. Can you get rid of the administration we have today? Meanwhile, it is positive that there is such an input [required] instead of the details [required] at the EU level because we do not like it. There is a great opportunity for Sweden to do something good about this if they/we have capacity.'

Policies and guidelines for work with environmental, economic and social sustainability are largely implemented and followed up by the support actors in the ecosystem. They agree that a prerequisite for sustainability and a functioning support system is to simplify and ensure the feasibility of the relevant policies, measures, etc. The ability to simplify is vital. This is exemplified through the following statements:

'It should be as simple as possible. We do not want it to be a barrier for the farmer. It is sometimes, and it is sad. It's a bit complex with support systems and rules, but there's not much we can do there more than talking about it upwards, and we've done that. We know how difficult it is, we are very humble.'

'New solutions or innovations create almost exclusively more bureaucracy. That's the dilemma. What would have to be more innovative is the simplification. It could be more innovative. Therefore, we are looking for simpler solutions. It's the innovation we want.'

'What would be more innovative is the simplification. This is where we need to invest in innovation within the support system.' 


\section{'A bit of lean production for bureaucracy. How can we make this work smoother?'}

A need for the development of a common collaboration model is identified based on observations and interviews. Uncertainty and lack of confidence exist between individuals and organizations, and sensitivity to and the understanding of different needs and roles in the ecosystem are lacking. While some collaboration efforts have been tested, the actors suggest a lack of overall perspective and collaborative intentions as reasons for the failure of these attempts at collaboration.

The observation and interviews outline the old traditions and culture, bureaucracy and individual influence that create a highly institutionalized ecosystem. The advisory organizations are more than 200 years old. The strong culture and the associated structures, methods and discourse make procedures complicated and bureaucratic. The individualistic culture is another problem identified within the system and has been confirmed by previous studies about Swedish agricultural advisory organizations (Höckert 2017). This is expressed through limitations in individual knowledge, individual interpretations, lobbying, culture and mind-set.

We identify a need to develop strategic management both within the organizations and in the overall agricultural entrepreneurship support ecosystem. Lack of leadership and leadership initiatives cause the institutionalisation and conservation of the old and individualistic culture, with the consequence of unutilized competence. The support actors clearly outline a common vision of creating sustainable rural areas in Sweden, while goal congruence, management and the fact that the actors are also competitors obstruct the collaborative effort to work towards the goals.

One challenge outlined is communication, especially communication between organizations, where no common communication platform or method of effective interaction and communication currently exist. Co-operation meetings and communication forums become individual-dependent and sensitive to changes in the people composing the group. However, there have been some initiatives for facilitating innovation within the ecosystem. Some of those mentioned are relationship building meetings and collaborative activities and meetings. There is a willingness within the system - primarily from the governmental point of view - to simplify. There are also individual initiatives aimed at encouraging innovation.

'What happens is that you get rid of the war, I would say [when communicating]. If you can use such a hard word. Because there are many misconceptions on both sides maybe. But perhaps also some relief that 'Well, that's how it works in your region:

'[Communication] It's necessary for understanding. It's enough to meet sometimes and tell how it is. It's not that difficult.'

We outline an initial conceptualization of the challenges identified in Table 1.1, which presents representative quotes and first-order concepts. The final step in the theoretical conceptualization is presented in Figure 1.2, which outlines a model for enabling innovation in a sustainable rural entrepreneurial support ecosystem. We identified early that the organizations have 'a common vision/mission' that is a starting point and a common ground for collaboration within the ecosystem. While this is not enough, the three blocks from Figure 1.1 highlight the need for managing the ecosystem to achieve a sustainable and innovative support system. The three blocks are a) a functioning collaboration model, b) methods for managing and developing 
an institutionalized system, and c) strategic management of organizations and the system. In addition, all three blocks must work together; thus, they must be embedded in a common communication platform, as discussed earlier. Facilitating actions that are adjusted to the situation are needed for the key actors to actually communicate, bring the advisory system together and accomplish change. There is both formal and informal leadership present in the model. The communication platform involves formal leadership with administrative routines and control. There, enabling leadership brings forward informal leadership. Finally, an adaptive space is created in the ecosystem, which provides the lubricant or the space where innovation can flourish. Adaptive space is created by stimulating pressure and simultaneously helping individuals act under the pressure. The model is based on CLT and aims to enable leaders to be skilful at formulating challenges and challenging enough to act as pressure and then help individuals act in a safe adaptive space while processing the pressure (Arena and Uhl-Bien 2016).

\section{Conclusion/discussion}

We contribute to the field of entrepreneurship by investigating the agricultural entrepreneurial support ecosystem, specifically the complex challenges faced and the interactions in the support system that take place when seeking to foster sustainable agricultural entrepreneurship (FitzKoch et al. 2018). The findings indicate that the agricultural entrepreneurial support ecosystem needs to adapt to changes in the environment to provide the support needed by agricultural entrepreneurs exposed to innovative challenges. The pressure in the environment requires changes in innovation practices and in the management and control of such changes in the support ecosystem, in Sweden and in other countries (Höckert 2017; OECD 2018). We highlight a number of challenges for creating a sustainable agricultural entrepreneurship ecosystem and identify a cognitive embeddedness, i.e., mental processes, among individuals and groups of actors. These impacts on the interaction between actors also hinder the mutual change process and the development of a common ground of economic reasoning (cf Zukin and DiMaggio 1990, pp. 15-16). We identify leadership structures and everyday practices shaping and reshaping the work processes that also hinder the adoption of new innovation practices.

Complexity and institutionalization, together with the lack of collaboration, communication and strategic management, are identified as recurring obstacles. There are stabilizing mechanisms in the ecosystem that strive to maintain familiar structures even as the organizations are forced to change under pressure. There is a need for innovation within the system to face challenges, make the system work and adapt to new opportunities and conditions. We identify cultural barriers consisting of internal and external competition within and between actors/organizations in the ecosystem. The poor strategic management cannot effectively coordinate key actors' interrelations and exchanges. Individual actors and organizations primarily consider their own personal brand, identity and benefits; 'what's in it for us'. The individualistic competitive culture within and between the support organizations spills over to challenge collaboration, learning and knowledge sharing (cf Höckert 2017), which in turn impact the support provided. We identify barriers that hinder agricultural entrepreneurial support ecosystems from thriving, affecting organizations' incentives for innovation and providing support for innovation. Like previous studies, we identify a strongly path-dependent support ecosystem, where social constructions are strongly manifested over a long period (Höckert 2017; Nee 1998, p. 86) based on the 200-year-old culture and traditions. The ecosystem is highly 
institutionalised, dominated by bureaucratic behaviour, encapsulating routinized acting and behaviour according to cognition and norms. This is also the case in other types of entrepreneurship support organizations (Johansson et al. 2019; Malmström et al. 2017). We identify a need to develop adaptive practices that nurture the informal adaptive system and bring forth creativity. There is also a need to combine these informal systems with formal administrative systems that develop goals and routines that challenge established practices. Bridging leadership can connect different perspectives to facilitate collaboration without merging or reducing the perspectives (Ospina and Foldy 2010). The results indicate a need to create an adaptive space for reflection and learning (Höckert 2017). In this innovative way of working, prestige and old structures may be questioned, and leadership may be developed within the ecosystem.

We can conclude that the entrepreneurial support ecosystem has not developed in parallel with the changes of the world surrounding agricultural entrepreneurship and its support system as expected after Sweden's entry into the EU in 1995, which opened up a free market. Under the right conditions and connections, the key actors may become cohesive groups that contribute to the development of the system (Arena and Uhl-Bien 2016; Fleming et al. 2007). We agree with Arena and Uhl-Bien (2016) that 'pressures are at the heart of adaptive space'.

This study sheds light on the importance of bringing agriculture into entrepreneurship and enriches entrepreneurship theory by modifying the theory to fit the agricultural entrepreneurship context (Fitz-Koch et al., 2018; Welter et al. 2017). Much previous work has focused on this ecosystem. We provide knowledge on the behaviour of the key actors in the support ecosystem by offering a new theoretical model of the dynamics in the ecosystem that is based on inductive analyses and CLT (cf Arena and Uhl-Bien, 2016). With this study as a starting point, future work can focus on creating a sustainable innovative system. We conclude in line with Burns (2005) that If organizations are too stable, nothing changes and the system dies; if too chaotic, the system will be overwhelmed by change. In both situations, an organization can only survive and prosper if a new, more appropriate, set of order-generating rules is established'.

Like any study, ours is not without limitations. First, we limit the study to the Swedish agricultural entrepreneurial support ecosystem. The Swedish context is highly embedded in the European system, and this may provide some ground for the generalization of the research together with findings from previous studies in other countries. We suggest that future research explore the agricultural entrepreneurship advisory system in other international contexts and test and develop our conceptual model in a broader contextual setting. Second, the conceptual model adopts an organizational perspective of the entrepreneurial support system, while the field would benefit from digging deeper into the cognitive foundations of social construction and action within the ecosystem. We suggest that further studies explore the cognitive level to reveal conscious and less unconscious dimensions. Finally, the study focuses on the key actors in support organizations, while there is a need to further highlight the expectations, needs and wants the agricultural entrepreneurs have concerning the agricultural entrepreneurial support ecosystem. In line with this, we recommend that future studies consider the entrepreneurs' perspective as a complement to the current study.

\section{References}

Allen, T. D. (2001), 'Family-supportive work environments: the role of organizational perceptions', Journal of Vocational Behavior, 58 (3), 414-435. 
Arena, M. J. and M. Uhl-Bien (2016), 'Complexity leadership theory: shifting from human capital to social capital', People and Strategy, 39 (2), 22-29.

Berger, P. L. and T. T. Luckmann (1966), The Social Construction of Reality: a Treatise in the Sociology of Knowledge, New York, NY: Double and Company.

Burnes, B. (2005), Complexity theories and organizational change. International journal of management reviews, 7(2), 73-90.

Carley, K. M. and V. Hill (2001), 'Structural change and learning within organizations', in Lomi, A. and Larsen, R. E. (eds.), Dynamics of Organizations: Computational Modeling and Organizational Theories, Menlo Park, Calif. ; London: AAAI Press/MIT Press.

Cederholm Björklund, J. (2018), 'Barriers to sustainable business model innovation in Swedish agriculture', Journal of Entrepreneurship, Management and Innovation, 14 (1), 65-90.

Cilliers, P. (1998), Complexity and Postmodernism: Understanding Complex Systems, New York, NY: Routledge.

Denzau, A. T. and D. C. North (1994), 'Shared mental models: ideologies and institutions', Kyklos, 47 (1), $3-31$.

Dias, C. S. L., R. G. Rodrigues and J. J. Ferreira (2018), 'What's new in the research on agricultural entrepreneurship?', Journal of Rural Studies, 65, 99-115.

Fitz-Koch, S., M. Nordqvist, S. Carter and E. Hunter (2018), 'Entrepreneurship in the agricultural sector: a literature review and future research opportunities', Entrepreneurship Theory and Practice, 42 (1), 129-166.

Fleming, L., S. Mingo and D. Chen (2007), 'Collaborative brokerage, generative creativity, and creative success', Administrative Science Quarterly, 52 (3), 443-475.

Food and Agricultural Organization of the United Nations (FAO) (2016), FAO Statistical Yearbook 2012, Part 1-The Setting, accessed 9 July 2019 at www.fao.org/docrep/015/i2490e/i2490e00.htm.

Gartner, W. B., P. Davidsson and S. A. Zahra (2006), 'Are you talking to me? The nature of community in entrepreneurship scholarship', Entrepreneurship Theory and Practice, 30 (3), 321-331.

Gioia, D. A., K. G. Corley and A. L. Hamilton (2012), 'Seeking qualitative rigor in inductive research', Organizational Research Methods, 16 (1), 15-31.

Government Offices of Sweden (2018), Sveriges regioner kraftsamlar inför programperioden 2020-2026, accessed 9 July 2019 at https://www.regeringen.se/artiklar/2016/05/sveriges-regionerkraftsamlar-infor-programperioden-2020-2026/.

Höckert, J. (2017), Sharing Lifeworlds and Creating Collaborative Cultures. Doctoral thesis, Uppsala: Swedish University of Agricultural Sciences.

Hörnsten, C. (2017), 'Slututvärderingar av landsbygdsprogrammet 2007-2013 - en sammanfattning', Jordbruksverket, 36. ISSN 1102-3007. ISRN SJV-R-11/1-SE. RA17:1

Jack, S. L. and A. R. Anderson (2002), 'The effects of embeddedness on the entrepreneurial process', Journal of Business Venturing, 17 (5), 467-487.

Johansson, J., M. Malmström, J. Wincent and V. Parida (2019), 'How individual cognitions overshadow regulations and group norms: a study of government venture capital decisions', Small Business Economics.

Kontopoulos, K. M. (2006), The Logics of Social Structure, England: Cambridge University Press.

Korsgaard, S., R. Ferguson and J. Gaddefors (2015), 'The best of both worlds: how rural entrepreneurs use placial embeddedness and strategic networks to create opportunities', Entrepreneurship \& Regional Development, 27 (9-10), 574-598.

Korsgaard, S., S. Müller and H. W. Tanvig (2015), 'Rural entrepreneurship or entrepreneurship in the rural - between place and space', International Journal of Entrepreneurial Behavior \& Research, $21(1), 5-26$.

Malmström, M., J. Johansson and J. Wincent (2017), 'Gender stereotypes and venture support decisions: how governmental venture capitalists socially construct entrepreneurs' potential', Entrepreneurship Theory and Practice, 41 (5), 833-860. 
Mumford, M. D., K. E. Bedell-Avers and S. T. Hunter (2008), 'Planning for innovation: a multi-level perspective', Research in Multi Level Issues, 7 (7), 107-154.

Nee, V. (1998), 'Norms and networks in economic and organizational performance', The American Economic Review, 88 (2), 85-89.

OECD (2018), Innovation, Agricultural Productivity and Sustainability in Sweden, Paris: OECD Food and Agricultural Reviews, OEC Publishing.

OECD (2019), Innovation, Productivity and Sustainability in Food and Agriculture: Main Policy Lessons from Selected OECD Country Reviews, accessed 9 July 2019 at https://issuu.com/oecd.publishing/docs/innovation_productivity_and_sustai.

Ospina, S. and E. Foldy (2010), 'Building bridges from the margins: the work of leadership in social change organizations', The Leadership Quarterly, 21 (2), 292-307.

Phillipson, J., M. Gorton, M. Raley and A. Moxey (2004), 'Treating farms as firms? The evolution of farm business support from productionist to entrepreneurial models', Environment and Planning C: Government and Policy, 22 (1), 31-54.

Stacey, R. D., D. Griffin and P. Shaw (2000), Complexity and Management: Fad or Radical Challenge to Systems Thinking, London and New York: Routledge.

Swedish Board of Agriculture (2018a), Statistiken med kommentarer, accessed 9 July 2019 at http://www.jordbruksverket.se/webdav/files/SJV/Amnesomraden/Statistik, \%20fakta/Foretag\%20 och\%20foretagare/JO34/JO34SM1801/JO34SM1801_kommentarer.htm.

Swedish Board of Agriculture (2018b), Sweden - Rural Development Programme (National). 5.1, accessed 9 July 2019 at http://www.jordbruksverket.se/download/18.4c6ca46b16724f1cf99de438/1542721517340/Progra mme_2014SE06RDNP001_5_1_sv.pdf.

Uhl-Bien, M. and R. Marion (2009), 'Complexity leadership in bureaucratic forms of organizing: a meso model', The Leadership Quarterly, 20 (4), 631-650.

Uhl-Bien, M., R. Marion and B. McKelvey (2007), 'Complexity leadership theory: shifting leadership from the industrial age to the knowledge era', The Leadership Quarterly, 18 (4), 298-318.

Welter, F. (2011), 'Contextualizing entrepreneurship-conceptual challenges and ways forward', Entrepreneurship Theory and Practice, 35 (1), 165-184.

Welter, F., T. Baker, D. B. Audretsch and W. B. Gartner (2017), 'Everyday entrepreneurship — a call for entrepreneurship research to embrace entrepreneurial diversity', Entrepreneurship Theory and Practice, 41 (3), 311-321.

Zahra, S. A. (2007), 'Contextualizing theory building in entrepreneurship research', Journal of Business Venturing, 22 (3), 443-452.

Zukin, S. and P. DiMaggio (1990), 'Introduction', in Zukin, S. and DiMaggio, P. (eds.), Structures of Capital: The Social Organization of the Economy, Cambridge, UK: Cambridge University Press. 